SPOR BİLIMLERİ ARAŞTIRMALARI DERGISI
Journal of Sport Sciences Researches
JSttp://dergipark.gov.tr/jssr
ISSN: $2548-0723$

\title{
Yaşlanma ve Egzersiz
}

\author{
Mustafa Savaş TORLAK ${ }^{1^{*}}$ \\ ${ }^{1}$ KTO Karatay Üniversitesi, Sağllk Hizmetleri Meslek Yüksekokulu, ORCID iD: 0000-0002-8084-6203
}

$\ddot{\mathbf{O z}}$

Derleme

Yaşlanma, biyomoleküler düzeyde yapısal ve fonksiyonel bozulmayla birlikte kanser, nörodejeneratif bozukluklar, sarkopeni ve karaciğer yetmezliği gibi birçok patolojik durumu içeren karmaşık bir süreçtir. Yaşlanma süreci vücut sistemlerinin işleyişini değiştirdiğinden (kardiyorespiratuar, kas iskelet sistemi, sinir sistemi, bağışıklık sistemi, endokrin sistem v.b.) yaşlı insanlarda fonksiyon bozuklukları ve yetersizlikler görülür. Yaşlanma sürecinde görülen kalp yetersizliği, diyabet, osteoporoz gibi hastalıklar daha çok hareketsizliğin sonucudur. İleri yaşlara kadar aktif kalmak ve bağımsız yaşam için fonksiyonel kapasiteyi arttırmak gerekir. $\mathrm{Bu}$ nedenle bağımsız bir yaşamın sürdürülmesinde yaşam boyu fiziksel aktivite önemlidir. Fiziksel aktivite sadece sağlıklı yaşlılarda değil kronik hastalığı olan yaşlılarda da son derece yararlıdır. Bu derleme, yaşlıların hangi tip egzersizleri yapması gerektiğini ve egzersizin yaşlanma süreci üzerine etkilerini çeşitli çalışmalar ışığında açıklamaya çalışacaktır.

Anahtar kelimeler:

Egzersiz, sağlık, yaşlanma.

\section{Aging and Exercise}

$\begin{array}{lr}\text { Abstract } & \begin{array}{c}\text { Review } \\ \hline \text { Aging is a complex process involving several pathological conditions such as cancer, } \\ \text { neurodegenerative disorders, sarcopenia and liver failure, along with structural and functional } \\ \text { impairment at the biomolecular level. As aging process changes the functioning of the body }\end{array} \\ \begin{array}{l}\text { systems (cardiorespiratory, musculoskeletal system, nervous system, immune system, } \\ \text { endocrine system etc.), older people experience dysfunction and disability. It is necessary to }\end{array} & \begin{array}{r}\text { Online Published: } 30.06 .06 .2018 \\ \text { Accepted: } 23.2018\end{array} \\ \text { remain active until advanced ages and to increase the functional capacity for independent } \\ \text { living. For this reason, lifelong physical activity is important in maintaining an independent } \\ \text { life. Physical activity is extremely useful not only in healthy elderly people but also in elderly } \\ \text { people with chronic diseases. This review will attempt to clarify what kind of exercises the } \\ \text { elderly should perform and the effects of the exercise on the aging process in the light of } \\ \text { various studies. }\end{array}$

\section{GíRiş}

\footnotetext{
* Sorumlu Yazar: Mustafa Savaş TORLAK, E-mail: mustafa.savas.torlak@karatay.edu.tr, Tel: +905373660138.
} 
Yaşlanma, temel mekanizması tam olarak bilinmeyen ve biyolojik işlevlerin bozulmasına yol açan çok faktörlü karmaşık bir süreçtir (Hadem, Majav, Kharbuli ve Sharma, 2017). Yaşlanma kavramı karmaşık bir biyo-psiko-sosyal süreç olduğu için tek bir tanımlama yapılamamaktadır. Genellikle, sosyal, kronolojik, fizyolojik ve psikolojik yaşlanma olarak alt gruplara ayrılmaktadır (Soyuer ve Soyuer, 2008). Sosyal yaşlanma, kişilerin sosyal rollerine ve alışkanlıklarına göre tanımlanır ve bireylerin hayatları boyunca sorumluluklarının ve yaşadıkları olayların sonucunda aldıkları (baba, büyükanne, emekli gibi) unvanlardır (Soyuer ve Soyuer, 2008). Psikolojik yaşlanma, kişilerin duygularında, algılamalarında ve davranışlarındaki değişiklikleri içerir (Soyuer ve Soyuer, 2008). Bu açıdan bireyin fiziksel kayıpları yanında ortaya çıkan davranışsal uyum yeteneğindeki yaşa bağlı değişimler, diğerlerine yük olma endişesi, işe yaramama tedirginliği, yalnız kalma korkusu olarak sıralanabilir (Eyüboğlu, Şişli \& Kartal, 2012). Fizyolojik yaşlanma ise, insan bedeninin yap1 ve fonksiyonlarında kronolojik yaşla birlikte görülen değişimlerdir (Çilingir ve Bulut, 2017). Bunlar, aerobik kapasitede azalma, vücut postüründe değişimler, derinin esnekliğini kaybetmesi, yüzde kırışıklıkların oluşması ve yerine konulamayan hücre kayıpları olarak tanımlanabilir. Yaşlanmayla birlikte fiziksel aktivitede azalma görülür. Yaşlanmanın kas fonksiyonu ve kardiyovasküler dayanıkl1lık üzerine olan etkileri yüzünden fiziksel aktivite ve fiziksel uygunlukta azalma durumu ortaya çıar (Hauiter ve Bonnefoy, 2007).

İnsanlar yaşlanırken, nöromusküler sistem dikkate değer değişikliklere maruz kalır. Fonksiyonel olarak, sıklıkla eklem hareketlerinde limitasyon, kas gücü kaybı, hareketlerde yavaşlama ve stabilite azalması gibi durumlardır. Sonuç olarak, kişinin günlük yaşam aktivitelerinde bağımsızlığı kısıtlanır ve yaşam kalitesi de azalır (Papa, Dong ve Hassan, 2017). Bu derleme yaşlılığın insan bedeni üzerine olan olumsuz etkilerini ve egzersizin yaşlılıktaki olumlu etkilerini bir potada eriterek yaşlıların ne tür egzersizler yapmaları gerektiğini açıklamaya çalışacaktır.

\section{Yaşlanma ile Görülen Fiziksel Değişiklikler}

Yaşlanma sonucunda endotelyal hücre bozulması, kalp kapakları, aort ve sol ventrikül kalınlığının artması gibi morfolojik değişiklikler görülür (Dai ve diğerleri, 2015). Yaşın ilerlemesiyle kalp kası kasılma süresinde ve refrakter periyotta uzama, vasküler tonusta azalma mekanik değişikliklerden sayılabilir (Lautenschlager ve diğerleri, 2008). Ayrıca sempatik aktivitede ve kan basıncında artma gözlenirken istirahat kalp debisinde, maksimal kalp atım sayısında ve kan hacminde azalma görülmektedir (Fleg, 2017).

Kalp hızı otonom sinir sistemindeki dejeneratif değişiklikler nedeniyle yavaşlamaktadır. $\mathrm{Bu}$ değişiklikler, iletim yollarındaki atriyoventriküler iletimin uzamasına, kalp hızı değişkenliğine, egzersize bağlı kalp hızı cevabında ve buna bağlı maksimum oksijen tüketiminde $\left(\mathrm{VO}_{2 \max }\right)$ azalmaya neden olmaktadır (Zoghi, 2010). Yaşlanmayla dayanıklılığın azalmasının altında yatan ana fizyolojik neden $\mathrm{VO}_{2 \text { max }}$ 'taki azalmadır (Hawkins ve Wiswell, 2003).

Yaş dekadlarına göre VO2max’ta azalma hızına bakan bir çalışmada, ikinci ve üçüncü dekatlardaki azalma hızının \%3'ten \%6'ya, yedinci dekat sonrasında \%20'nin üzerine 
çıktığını bildirmiştir (Fleg ve diğerleri, 2005). Yine benzer bir çalışmada VO2max'taki azalma oranı erkeklerde (\%14) daha hızlı iken kadınlarda (\%7) daha az olduğu gösterilmiştir (Stathokostas, Jacob-Johnson, Petrella ve Paterson, 2004).

Yaşlandıkça akciğerin kompozisyonu değişir, solunum kaslarının kuvveti azalır. Pulmoner arter ve venler sertleşir. Bronşial arterler hücrelere gerekli besini sağlamada zorlanırlar (Chodzko-Zaiko ve diğerleri, 2009). İlerleyen yaşla birlikte akciğerlerde siliar aktivite azalır. Vücudun savunma sistemi zayıflar. Bu iki değişiklik, akciğer enfeksiyonu oluşma riskini arttırır. Yaşla solunum yeteneğinde olan azalma özellikle kardiyovasküler sistem bozukluğu olan yaşlilarda belirgindir (Tilley, Walters, Shaykhiev ve Crystal, 2015). Solunum mekaniğindeki ve pulmoner dolaşımdaki değişiklikler akciğerlerin kapanma eğiliminde artışa ve gaz değişiminde azalmaya yol açar. Bu bulgular hem egzersiz hem de dinlenme sırasında akciğer fonksiyonunu etkiler (Fernandez-Bustamante, Sprung, Cartin-Ceba, Weingarten ve Warner, 2018; Skloot, 2017).

Yaşlanmayla birlikte kas kuvvetinde ve hacimindeki azalmanın nedenleri; sedanter yaşam, sinir sistemindeki gerileme, büyüme hormonu, androjenler ve östrojen hormonlarının azalması, bazal metabolik hızın düşmesi, fonksiyonel kapasitenin azalması şeklinde siralanabilir (Nair, 2005; Saini, Faulkner, Al-Shanti ve Stewart, 2009). Ayrica, son yıllarda yapılan bir çalışmada, yaşlılarda oluşan kas kaybının dolaşımda enflamatuar sitokin üretiminin artması sonucu meydana geldiği bildirilmiştir (Wang, Leung, Chow ve Cheung, 2017).

Kas kuvvetindeki ilerleyici azalma yaşamın altıncı dekadından sonra hızlanır. Ekstansör kas grupları, özellikle diz ve ayak bileği ekstansörleri daha ciddi olarak etkilenir. Bu kas grupları günlük yaşam aktivitelerinde sık kullanıldıkları için önemlidirler (Katula, Rejeski ve Marsh, 2008). Üçüncü dekattan sonra her on yılda aerobik kapasite ortalama \%8 civarında azaldığı varsayılmaktadır (Hollmann, Strüder, Tagarakis ve King, 2007).

Yaşın ilerlemesiyle birlikte çizgili kaslarda ekstraksiyon-kontraksiyon çiftlerinde ve kalsiyum algılayıcı reseptörlerdeki azalma gibi hücresel düzeyde bozulmalar da görülmektedir. Küçük motor ünitelerin azalması ile kas koordinasyonu ve stabilitesindeki kayıp belirgin hale gelmektedir (Goldspink, 2005). Kas kuvvetinde düşüş altıncı dekat sonrasında belirgin olmaktadır (Hollmann ve diğerleri, 2007; Nair, 2005). Kas rezervleri daha az olduğundan kadınlarda özellikle altıncı dekatta kas kuvvetinde gerileme daha hızlıdır (Goldspink, 2005).

Yaşlanmayla merkezi sinir sistemi nöronlarında da kayıplar gözlenir. Beyin ağırlığı, 70 yaşında genç bir yetişkine göre yaklaşık \%10 azalır. Bu oran 80 yaşında \%17'ye kadar çıkabilir. Yaşla birlikte öğrenme ve bilgi depolama yeteneğinde kayıplar görülür (Arpac1, 2005). Beynin yanında hipokampusda etkilenerek beyin performansının bozulmasında rol oynar (Hollmann ve diğerleri, 2007).

Yaşla birlikte görülen morbiditelerden biri de osteoporozdur. Kemik kırıkları yaşlı bireylerde osteoporozla direk bağlantılıdır (Novotny, Warren ve Hamrick, 2015). Osteoporoz, kemikteki mikro-yapısal değişikliklere bağlı kırılgan kırılma riskini arttıran bir hastalıktır (Licata ve Williams, 2013). İki bin yirmi yılında dünya çapında 14 milyon bireyin osteoporoz olması beklenmektedir (Diab ve Watts, 2013). Yaşın ilerlemesiyle özellikle kadınlarda femur 
boynunda ve omurgadaki kemik dokuda mineral yoğunluğu her yıl yaklaşık olarak \%1-2 arasında azalır (Finkelstein ve diğerleri, 2008).

Sarkopeni ve inflamasyon yaşlı patofizyolojisinde önemlidir. Yaşlanma sürecinde kas proteinlerinin azalması, iskelet kasıyla yağ ve konnektif dokunun yer değiştirmesi ve buna bağlı kasın hacminin azalması sarkopeni olarak adlandırılır (Roubenoff, 2003). Sarkopenide, kas yapısı, tendonların mekanik özellikleri, nöral bağlantılar ve tek kas lifinin gücü belirgin olarak bozulur (Narici ve Magaranis, 2006).

Fiziksel aktivitenin arttırılması durumunda inflamasyon belirteçlerinin (IL-6, IL-11) daha düşük seviyede olduğu belirlenmiştir (Elosua ve diğerleri, 2005). Visser ve diğerlerinin (2002) çalışmasında 70-79 yaş grubunda IL-6 ile kas kütlesi ve kas gücü arasında ters ilişki olduğu görülmüştür . Yaş ilerledikçe, $\mathrm{C}$ reaktif proteinde (CRP), proinflamatuar sitokinlerde, monosit ve nötrofil sayılarında, pıhtılaşma ve enflamasyon belirteçlerinde, vücut yăg kitlesinde artış görülürken, insülin benzeri büyüme faktörü (IGF-1), testosteron, büyüme hormonu seviyelerinde düşme görülür (Fried ve diğerleri, 2009; Topinkova, 2008).

\section{Yaşlılık ve Egzersiz}

Fiziksel inaktivite, sarkopeni ve fonksiyonel yetersizlik gibi birçok kronik dejeneratif hastalığın önde gelen nedenlerinden biri olarak kabul edilir (Marzetti ve diğerleri, 2017). Yaşın ilerlemesiyle fiziksel aktivitede görülen azalmanın sedanter yaşam tarzı mı, yoksa yaşlanmanın içsel etkileri mi olduğunu belirlemek güçtür (Goldspink, 2005). Kasın mitokondiriyal fonksiyonlarının azalması ile yaşlılarda spontan aktivitelerde azalma olur. $\mathrm{Bu}$ azalma ile birlikte istemli hareketin başlaması etkilenebilir (Nair, 2005). Yaşlanma sürecinde fiziksel gerilemelere sebep olan birçok faktör olmasına karşın, aktif olan yaşlılarda yaşlanma sürecinin yavaş olduğu görülmektedir (Taylor ve diğerleri, 2004). Düzenli fiziksel aktivite kardiyovasküler hastalıklar, felç, diyabet, çeşitli kanserler, depresyon ve düşme riskini azaltmaktadır (Marzetti ve diğerleri, 2017). Egzersiz, yaşa bağlı kas kütlesi kaybını azaltarak ve insülin duyarlılığını arttırarak, yaşlanmanın zararlı etkilerine karşı gelir ve sağlıklı yaşlanma olanağı sağlar (Cartee, Hepple, Bamman ve Zierath, 2016). Düzenli ev egzersiz programı, düşme riski bulunan yaşlılarda dengeyi geliştirir (Elsawy ve Higgins 2010).

Yaşlılarda kalp sağlığına egzersizin faydaları genç bireylerde beklenen sonuçlarla aynıdır dahası yaşam kalitesi ve fiziksel fonksiyondaki düzelmeler daha fazladır (Williams ve diğerleri, 2002). Fakat fonksiyonel kapasitedeki artış (maksimum oksijen tüketimi) gençlere kıyasla daha azdır, bu nedenle özellikle 75 yaşın üzerindeki yaşlılarda egzersiz programının daha uzun süreli olması tavsiye edilmektedir (Audelin, Savage ve Ades, 2008). Kalp yetmezliği olan yaşlılarda egzersiz eğitiminin fizyolojik, fonksiyonel ve klinik sonuçlar açısından faydaları olduğu açık bir biçimde bilimsel olarak desteklenmesine rağmen, kalp yetmezliği olan yaşlı hastaların egzersiz eğitimini kabullenme oranının düşük olduğu görülmektedir (Coats ve diğerleri, 2017).

Hastane yatıştan hemen sonra gerçekleştirilen 12 haftalık egzersiz antremanı sonrası fonksiyonel kapasitede \%10-60'lık artış, kalbin iş yükünde \%10-25'lik azalma 
görülebilmektedir (Williams ve diğerleri, 2002). Yaşlilarda düzenli egzersizin kardiyovasküler etkileri Tablo 1'de görülmektedir (Chodzko-Zaiko ve diğerleri, 2009).

Tablo1: Yaşlılarda düzenli egzersizin kardiyovasküler etkileri

1. Maksimal oksijen tüketimin artması
2. Submaksimal egzersizde kalp atımının azalması
3. Kan basıncının düşük olması
4. Kasta oksijenlenmesinin artması
5. HDL seviyesinin artması
6. Trigliserit seviyesinin düşmesi
7. Arterlerin sertliğinin azalması
8. İstirahat kalp hızının azalması
9. Endotel fonksiyonlarının düzelmesi
10. Barorefleks fonksiyonlarının düzelmesi
11. Vagal tonusun artması
12. Miyokard kasılmasının düzelmesi
13. Maksimal egzersiz sırasında atım hacminin artışı

Yaşın ilerlemesine rağmen iskelet kasları, egzersize uyum sağlama ve plastisite özelliğini korur (Bottaro ve diğerleri, 2007; Mechling ve Netz, 2009). Ağırlık antrenmanı ve aerobik egzersizin neden olduğu protein sentezi gençlerde olduğu gibi yaşlılarda da görülmektedir. Yaşlılarda, tek bir ağırlık kaldırma seansının kas protein sentezini belirgin derecede uyardığı, yaklaşık 48 saat sonra yapılan ikinci antremanda da protein sentezinin tekrar uyarıldı ğ görülmüştür (Hollmann ve diğerleri, 2007). Yaşları 65 ile 75 yaş arası değişen sağlıklı yaşlılarda 3 ay boyunca haftada iki kez yapılan ilerleyici direnç antremanının kas kuvvetinde artışa neden olduğu bildirilmiştir (Forte ve diğerleri, 2013). Yine yaşları 60 ila 74 arasında değişen kadınlarda aerobik ve güç antremanının kombine edilmesiyle yağsız kas kitlesinde, kas kuvvetinde ve aerobik güçte artış, yağ oranında azalma görülmüştür (Hunter ve diğerleri, 2013). Ancak eksentrik egzersiz verilirken dikkatli olunmalıdır çünkü eksantrik kaynaklı kas hasarı, sarkopeninin genel semptomlarını ağırlaştırabilir.

Dünya genelinde elli yaşını geçmiş olan erkeklerin yaklaşı \%40'ında osteoporotik kırıklar görülmektedir ve bu kırıklardan dolayı ölen erkeklerin oranı kadınlara göre daha yüksektir (Boonen ve diğerleri, 2012). Egzersizin kemik kaybını yavaşlatıp, kırık riskini azalttığını gösteren çalışmalar mevcuttur (Kai, Anderson ve Lau, 2003; Liu ve diğerleri, 2011). Fiziksel aktivite ayrıca östrojen artışı ile birlikte insülin ve androjen gibi endokrin faktörleri serbestleştirerek kemik ve kasların kuvvetlenmesine neden olur (Vainionpaa ve diğerleri, 2007). Düzenli yapılan aerobik egzersizler örneğin yürümek, hızlı yürümek ve koşmak özellikle kadınlarda kemik yoğunluğunu artırır. Ayrıca kemik kitlesini geliştirerek kırıklardan koruyabilir (Kai ve diğerleri, 2003). Kalça kırıklarının \%90'1 düşmelerden kaynaklanmaktadır ve 65 yaş üzeri yaşlılarda ölüm nedenleri arasında düşmeler altıncı sırada yer almaktadır (Barnett ve diğerleri, 2003; Carter ve diğerleri, 2002). Özellikle osteoporozlu kişilerin düşme sonucu kırık riski ile karşılaşmaları nedeniyle egzersiz antrenmanının bu konudaki önemi büyüktür (Carter ve diğerleri, 2002). Barnett ve diğerleri (2003), geriatrik yaş grubunda grup egzersiz antremanının denge, kas kuvveti, reaksiyon zamanı, fiziksel 
fonksiyon, sağlık durumu ve düşmelerin önlenmesi üzerine etkilerini incelemiş ve egzersiz sonrası bu parametrelerde olumlu gelişmelerin olduğunu belirtmişlerdir. Şiddetli egzersizler, yaralanma ve düşme riskini arttırdığ 1 için osteoporozlu yaşlılarda önerilmemektedir (Nelson ve diğerleri, 2007).

Yaşlı bireylerde depresyon sık görülen bir hastalıktır (Reynolds ve diğerleri, 2006). Yaşlanmayla, hipokampal atrofi ve disfonksiyon artar. Hipokampal bozulmanın en önemli nedeni, beyin kaynaklı nörotrofik faktör (BDNF) proteininde veya reseptöründeki yaşa bağlı değişimlerdir. BDNF'nin azalmasıyla hafiza bozuklukları ve depresyon riskinde artma görülmektedir (Erickson, Miller ve Roecklein, 2012). Fiziksel aktivitenin yaşı bireylerde depresyon riskini azaltabileceğini gösteren çalışmalar mevcuttur (Eyigor ve diğerleri, 2009; Strawbridge, Deleger, Roberts ve Kaplan, 2002). Aerobik egzersiz, BDNF seviyelerini yükselterek hipokampal atrofiyi, depresyon riskini azaltır (Erickson ve diğerleri, 2012). 165 yaşı birey üzerinde yapılan bir çalışmada, yüksek aerobik kapasitesi olan yaşlılarda hipokampal atrofinin daha az olduğu ve hafiza fonksiyonlarının daha iyi olduğu görülmüştür (Erickson ve diğerleri, 2009). Hafif derecede kognitif bozukluğu olan yaşlı kadınların katıldığı bir çalışmada, katılımcılar aerobik egzersiz veya germe egzersizi gruplarına ayrılmışlar ve 6 ay boyunca düzenli egzersiz yapmışlardır. Sonuçta aerobik egzersiz grubunda, germe egzersizi yapan gruba göre kognitif fonksiyonlarda iyileşme görülmüştür (Baker ve diğerleri, 2010). Başka bir çalışmada ise, uzun süreli egzersiz yapan yaşlı sıçanların hipokampüs bölgesindeki reaktif oksijen türlerinin ve protein karbonil miktarının sedanter sıçanlara göre daha az olduğu görülmüş ve uzun süreli egzersizin sinir hücrelerini oksidatif strese karşı koruyabileceği ve yaşlanmayı geciktirebileceği sonucuna varılmıştır (Marosi ve diğerleri, 2012).

Prefrontal korteks üst düzey davranışları düzenleyen beynin önemli bir bölgesidir (Hooghiemstra ve diğerleri, 2012). Özellikle prefrontal korteks aracılı̆̆ıly yapılan işlevler fiziksel aktiviteden olumlu şekilde etkilenmektedir (Colcombe ve diğerleri, 2003). Pariyetal lob gibi diğer kortikal bölgelerinde fiziksel aktiviteden pozitif olarak etkilendiği bildirilmiştir (Rosano ve diğerleri, 2010). Yaşlı bireylerde öğrenme ve beyin fonksiyonları üzerine aerobik egzersiz antrenmanının olumlu etkisi olduğu belirtilmiştir (Hillman, Erickson ve Kramer, 2008).

Fiziksel inaktivite, yaşlı bireylerde kognitif fonksiyonlar üzerine olumsuz etki gösterebilir. Hafif derecede kognitif bozukluğu olan yaşı bireylerde fiziksel performansın azalmasının Alzheimer riskini artırabileceği çalışmalarda belirtilmiştir (Aggarwal ve diğerleri, 2006; James ve diğerleri, 2011). Yaşlı bireylerin 12 ay boyunca normal yürüyüş hızlarını arttırmalarının mortalite oranında azalmaya neden olabileceği gösterilmiştir (Hardy ve diğerleri, 2007). Bundan dolayı fiziksel aktivitenin arttırılması yaşı bireylerde kognitif bozukluğun oluşmasını engelleyebilir.

İnsanlar yaşlandıkça kas kuvveti ve aerobik kapasite fizyolojik olarak azalır (Sui ve diğerleri, 2007). Düşük aerobik kapasiteli yaşlılar fiziksel hareketten kaçma eğilimindedirler. Bu durum kas hacim ve kuvvetlerinin düşmesine, dolayısıyla aerobik kapasitelerinin azalmasına yol açar. Halbuki yaşlıların günlük hayatta bağımsız hareket etmesi büyük oranda aerobik kapasite ve kas gücüne bağlıdır (Vogel ve diğerleri, 2009). Yaşlılarda oluşan bu kısır döngü 
düzenli egzersizle aerobik kapasitede üçte bire yakın düzelme, kas gücünde ise $\% 25$ ile \%100'e varan iyileşmelerle kırılabilir (Chodzko-Zaiko ve diğerleri, 2009; Liu ve Latham, 2009). Bu faydalarının yanı sıra, orta şiddette düzenli egzersiz yapmak yaşlı erişkinlerde kardiyovasküler morbidite ve mortalite ile diyabet insidansını düşürür, kan basıncı değerlerini ve lipit profilini düzeltir (Vogel ve diğerleri, 2009).

Bilinen tüm bu yararlı etkilerine rağmen ülkemizde ve gelişmiş ülkelerde yaşlıların çok büyük bir bölümü düzenli egzersiz yapmamaktadırlar. Egzersizle tedavi, hastaların kendilerinin, yakınlarının hatta hekimlerin yarattığı engeller nedeniyle yeterince yararlanılamayan bir tedavi yaklaşımıdır. Yaşlıların egzersiz yapmasına engel olan durumlar ve çözüm yolları Tablo 2'de gösterilmiştir (Nied ve Franklin, 2002).

Tablo 2: Yaşlıların egzersiz yapmasına engel olan durumlar ve çözümleri

\begin{tabular}{cc}
\hline Engel & Çözüm \\
\hline Kendine güvenmemek & Kolay egzersizler \\
Negatif tavır & Eğlenceli egzersizler \\
Rahatsılık hissi & Yoğunluğunu değiştirmek \\
Bozuk denge & Yardımcı cihazlar \\
Yaralanma korkusu & Denge ve kuvvetlendirme \\
Kısıtlı gelir & Yürüyüş ve basit egzersizler \\
Kognitif gerilik & Basit egzersizler \\
Hastalık & Enerji seviyesine göre egzersiz \\
\hline
\end{tabular}

Egzersizin faydaları yanında bazı riskleri de bulunmaktadır. Ancak bu riskler önlenebilir. Yaşlı bireylerde potansiyel kontraendike durumlar ve risklerin denetimi için en önemli parametre, uygulanan egzersiz süresi ve düzeyidir (Gokkaya, 2009). Yaşlılarda risk faktörleri, sağlık problemleri, ağrılı eklemler, algıda zayıflık, denge bozuklukları ve hedefe yönelik hareketlerdeki bozulmaları içerir. Egzersiz ciddi sağlık problemine yol açacağı durumlarda yapılmamalıdır (Dunsky ve Netz, 2012). Yaşlıların egzersiz yapmaması gereken durumlar Tablo 3'te gösterilmiştir (Bean, Vora ve Frontera, 2004).

Tablo 3: Yaşliların egzersiz yapmaması gereken durumlar

\begin{tabular}{l}
\hline Şiddetli koroner arter hastalığı \\
Stabil olmayan anjina pektoris \\
Konjestif kalp yetmezliği \\
Kontrol edilemeyen atrial veya ventriküler aritmi \\
Şiddetli kalp kapak hastalığı \\
Kontrol edilemeyen sistemik hipertansiyon \\
Pulmoner hipertansiyon \\
Akut myokardit \\
Yeni pulmoner emboli ve derin ven trombozu \\
Aortik anevrizma \\
Serebral anevrizma veya intrakranial kanama \\
Akut veya stabil olmayan kas iskelet yaralanması \\
Akut retinal hemoraj veya oftalmik cerrahi \\
İleri derecede demans ve davranış bozuklukları \\
\hline
\end{tabular}


Sağlıklı bir yaşlanma süreci için düzenli aerobik ve kas kuvvetlendirme egzersizleri yapılmalıdır. Düzenli egzersiz ile kronik hastalık riski, mortalite, fonksiyonel kısıtlılıklar düzeltilebilir (Chodzko-Zaiko ve diğerleri, 2009).

Dünya Sağlık Teşkilatı yaşlıların fiziksel kapasitelerini 1. sağlıklı ve bağımsız, 2. sağlıksız ve bağımsız ve 3. sağlıksız ve bağımlı olarak üç grupta toplamaktadır (Chodzko-Zaiko,1997). Her grubun egzersiz ihtiyaçları birbirinden farklıdır. Birinci grupta amaç sağlığı egzersizle korumaktır. İkinci grup düzenli egzersiz yapmayan ve bağımsız olan ancak bağımsızlıklarını etkileyebilecek birçok kronik hastalığı bulunan yaşlılardır ve toplumda yaşayan yaşlıların büyük bir kısmını oluştururlar. Bu grupta düzenli egzersiz yapmak bağımsızlığ 1 sürdürmeye yardımcı olur. Son grup toplumda bağımsız yaşayamayan birilerine ihtiyaç duyan yaşlılardır. Üçüncü grupta egzersizin amacı günlük yaşam faaliyetleri ve hareketliliğin devam ettirilmesidir (Chodzko-Zaiko, 1997).

Amerikan Spor Hekimleri Birliği ve Amerikan Kalp Birliği yaşlılarda 4 tip egzersiz önermektedir (Chodzko-Zaiko ve diğerleri, 2009).

\section{Dayanıklılık Egzersizleri}

Haftanın 5 günü en az 30 dakika, yaşlı bireyin sağlığı uygunsa 60 dakika süren, 1lımlı aerobik egzersiz veya haftanın 3 günü 20 dakika süren şiddetli aerobik egzersiz önerilmektedir (Chodzko-Zaiko ve diğerleri, 2009).

Yaşl1lar için önerilen dayanıklılık egzersizleri, ortopedik baskı yaratmayacak herhangi bir egzersizdir. Yürüme veya ekleme yük bindirilmek istenmiyorsa havuz içi egzersizler ve sabit bisiklet egzersizleri olabilir. Otuz dakikalık egzersiz süresi yaşlının dayanıklılık düzeyine göre 10'ar dakikalık bölümlere ayrılabilir. Aerobik egzersiz 60 dakikayı geçmemelidir. Yoğunluk ve süre 2-3 haftada bir arttırılabilir (Chodzko-Zaiko ve diğerleri, 2009). Bu önerilen aerobik aktivitelere ilaveten günlük rutin olarak hafif yoğunlukta yapılan aktiviteler (örneğin kişisel bakım, yemek yapmak, alışveriş yapmak) ve 10 dakikalık orta yoğunlukta aktivitelerde (örneğin ev veya iş yeri etrafinda yürümek) önerilmektedir (Nelson ve diğerleri, 2007).

Dayanıklılık egzersizinin yapılma amacı sedanter bireylerde her dekadta VO2max'ta oluşan \%5 ila \%10’luk azalmanın önüne geçmek ve iyileştirmektir. Çünkü düşük aerobik kapasite mortalitede artış, kronik kalp hastalığı, düşük fonksiyonel kapasite ve merdiven çıkma, hızlı yürüyüş gibi günlük yaşam aktivitelerinde beceri azalması ile ilişkilidir (Nelson ve diğerleri, 2007). Evans ve diğerleri (2005), ortalama yaşları 80.3 olan 10 yaşlı kadına uyguladıkları 108 dayanıklılık egzersiz programı sonrasında VO2max’ta \%15'lik bir artış saptamışlardır.

\section{Direnç Egzersizleri}

Direnç egzersizlerinin iskelet kası kütlesi ve gücünde artışa katkıda bulunduğu yaygın olarak kabul edilmektedir (Csapo ve Alegre, 2016). Haftanın en az iki günü, uygun ağırlıklarla, 8-10 farklı türde egzersiz 10-12 tekrarla 1lımlı şekilde yapılmalıdır. Önerilen egzersiz tipleri ilerleyici ağırlık kaldırma, merdiven inip çıkma, yük bindiren egzersizler veya büyük kas gruplarının dahil olduğu diğer kuvvetlendirme egzersizleridir (Chodzko-Zaiko ve diğerleri, 2009). Kuvvetlendirme egzersizleri, bağımsızlığı artırabilecek şekilde oluşturulmalı ve kas gücünü dayanıklılığını artırmalıdır. Elli yaşından sonra primer sarkopeniye bağlı olarak kas 
kitlesi ve gücünde her dekadta \%15, 70 yaşından sonra her dekadta \%30'luk azalma söz konusudur (Cruz ve diğerleri 2010). Azalan kas gücü fiziksel yetersizliğe ve yaşam kalitesinde azalmaya yol açar (Delmonico ve diğerleri, 2007). Kas gücü özellikle 80 yaşın üzerinde çok önemlidir. Kas güçsüzlüğü yürüme, banyo yapma, giyinme, yemek pişirme gibi günlük faaliyetleri zorlaştırır. Kas kuvvetlendirici egzersizlerle kas gücünde \%25 ila \%100 oranında artış, kas hipertrofisi, nitrojen dengesinde düzelme söz konusudur (Liu ve Natham, 2009).

\section{Esneklik Egzersizleri}

Esneklik egzersizleri, fiziksel aktivite ve günlük aktiviteler sırasında eklem hareket açıklığının sağlanması için haftada en az iki gün ve her gün için en az 10 dakika sürecek şekilde yapılması tavsiye edilmektedir (Nelson ve diğerleri, 2007). Önerilen egzersiz tipi her büyük kas grubunu geren tipte ve germe egzersizleri statik şekilde olmalıdır. Germe egzersizlerinin amacı düşme riskini azaltmak, eklem hareket açıklığını korumak veya arttırmaktır (Chodzko-Zaiko ve diğerleri, 2009). Statik egzersizlerin yanı sıra dinamik egzersizlerin (pilates gibi) esneklik için fayda sağladığı belirtilmektedir (Oliveria, Oliveria ve Pires-Oliveria, 2016). Pilatesin yanı sıra Tai-Chi egzersizleri de yapılabilir (Kuramato, 2006). Tai-Chi, Çin'den köken almış ve savaşma sanatı olarak adlandırılan bir egzersiz şeklidir. İlk olarak kavga için kuvvet, denge ve hızı artırmak amacıyla yapılmış daha sonra her yaş grubu insanlar tarafından nazik, yavaş ve pratik bir egzersize dönüşmüştür. Dairesel hareketlerle denge gelişimine yardımcıdır (Taggart, 2002). Tai-Chi uygulamasıyla alt ekstremite kas gücü, denge artar, düşme sayısı azalır ayrıca kardiyovasküler sistem üzerine pozitif etkileri vardır (Kuramato, 2006). Yang tarzı Tai chi'nin sağlıklı yaşlı kadınlarda yürüyüş parametrelerini ve kas iskelet esnekliğini arttırmada etkili olduğu gösterilmiştir (Zou ve diğerleri, 2017).

\section{Denge Egzersizleri}

Yaşlı bireyler dengelerini korumak, geliştirmek ve düşmeye bağlı yaralanma riskini azaltmak için haftada iki kere denge egzersizi yapmalıdırlar (Cadore ve diğerleri, 2013). Denge egzersizleri sağlıklı yaşlı erişkinlerde performansın yanı sıra statik ve dinamik denge durumunu geliştirmektedir (Lesinski ve diğerleri, 2015). Yapılan bir çalışmada, direnç egzersizinin postural kontrolü geliştirmediği ancak denge egzersizlerinin yaşlı bireylerde postural kontrolu geliştirdiği gözlenmiştir (Low, Walsh ve Arkesteijn, 2017).

Önerilen egzersizler, tek ayak üzerinde duruş, yerçekimi merkezini bozan dinamik egzersizler, postüral kas gruplarını zorlayan hareketler (topuk üzeri duruş, parmak ucunda durma), duysal uyarıyı azaltma (gözler kapalı ayakta durma) gibi egzersizlerdir (ChodzkoZaiko ve diğerleri, 2009; Choi ve Kim, 2015). Maduirera ve diğerlerinin (2010) yaptığ randomize kontrollü çalışmada, bir klinikte 6 ay boyunca takip edilen 64 yaşlı kadın denge egzersiz grubu ve kontrol grubuna rastgele ayrılmışlardır. Bir fizyoterapist eşliğinde haftada bir kez, bir saatlik denge egzersizi yapan yaşlı bireylerin kontrol grubundakilere göre fonksiyonel dengelerinde gelişme görülmüştür. Direnç egzersizleri ile denge egzersizleri birleştirildiğinde denge üzerine daha iyi sonuçlar elde edildiği görülmüştür. Hasselgren ve diğerleri (2011), yaşı ve klinikte yatan bireylerde bacak kas kuvveti ve fonksiyonel denge ile 
mobilite arasındaki ilişki incelenmiş ve özellikle ayak bileği dorsi fleksörlerinin yürüme sırasında dengenin korunmasında önemli olduğu sonucuna varmışlardır. Bird ve diğerleri (2011) esneklik ve direnç antreman programına katılan yaşlı bireylerde denge, kuvvet, mobilite seviyelerine uzun vadeli etkilerini incelemişlerdir. Çalışmanın sonunda, düzenli kuvvet antremanı yapıldığında denge ve mobilitede düzelmeler olduğu görülmüştür. Yapılan güncel bir çalışmada, dengeye yardımcı egzersiz robotuyla (BEAR) yapılan egzersizlerin alt ekstremite kas kuvvetini artırmada ve dinamik dengeye geleneksel egzersizlere göre daha etkili olduğu ve yürüme sıkıntısı olan kırılgan yaşlılarda faydalı olabileceği bildirilmiştir (Ozaki ve diğerleri, 2017).

\section{Diğer Egzersizler}

Yaşlılarda uygulanan egzersiz programlarında eğer birey tolere edebiliyorsa yürüme egzersizi mutlaka olmalıdır. Düzenli yürüme, yaşlıların hayat kalitesini artırmaya yardımcı olabilir (Melzer, Benjuya ve Kaplanski, 2003).

Yürüme eğitiminin yaşlı bireylerde alt ekstremite gücünü arttırdığı belirtilmiştir (Abe ve diğerleri, 2010). Bakımevinde kalan ve ılımlı depresyonu olan 12 yaşlı kadın üzerinde yapılan araştırmada, kısa süreli yürüme eğitiminin hafif depresyonlu yaşlı kadınlarda anksiyetenin azalmasında etkili olduğu gösterilmiştir (Legrand ve Mille, 2009). Cobblestone (kaldırım taşı benzeri) yürüme egzersizinin dengeyi arttırdığı ve kan basıncı üzerine olumlu etkileri olduğunu gösteren çalışmalar mevcuttur (Li ve diğerleri, 2003; Li ve diğerleri, 2005). $\mathrm{Bu}$ aktivite, kaldırım taşı şeklindeki mat üzerinde çıplak ayakla yapılan bir yürüme egzersizidir ve geleneksel Çin tıbbında ayak tabanında bulunan akupunktur noktalarının uyarılmasına dayanan refleksolojiden köken almaktadır ( $\mathrm{Li}$ ve diğerleri, 2005). Ev egzersizlerinin ihtiyaca yönelik olarak verilmesi yaşlıların performansı açısından olumlu sonuçlar ortaya çıkarmaktadır (Henry, Rosemond ve Eckert, 1999). Altmışbeş yaş üzeri kişilerde yapılan çalışmada, ısınma, mobilite, germe, kuvvetlendirme, denge, endurans ve soğumayı içeren ev programı uygulanmış ve uygulanan programın yaşlılarda düşmenin önlenmesinde ve yaşam kalitesinin egzersizle arttırılmasında önemli gelişmeler görülmüştür (Iliffle ve diğerleri, 2010).

\section{SONUÇ VE ÖNERİLER}

Yaşın ilerlemesiyle çeşitli hastalıklar ve fiziksel aktivitede azalma görülür (Chodzko-Zaiko ve diğerleri, 2009). Egzersiz yapmak ve fiziksel olarak aktif kalmak, yaşlilarda kardiyovasküler hastalıklarda azalma, kas kuvvetinde artış, kognitif bozukluklarda ve kemik erimesinde azalma, maksimal oksijen tüketiminde ve dengede artma gibi olumlu etkilere neden olur (Chodzko-Zaiko ve diğerleri 2009; Goldspink, 2005; Hauiter ve Bonnefoy, 2007; Liu ve diğerleri, 2011; Nelson ve diğerleri, 2007).

Haftada en az iki gün güçlendirme egzersizi (Chodzko-Zaiko ve diğerleri, 2009) ve 1500 metre yürümenin fonksiyonel kısıtlılıkların ilerlemesinde yavaşlamaya neden olduğu belirtilmiştir (Espinoza ve Waltson, 2005). Tha Chi, güçlendirme ve dayanıklılık egzersizleri gelecek vaat eder gözükse de, yaşlılarda için en ideal egzersiz sorusu halen cevapsız kalmaktadır. Ancak koruyucu yaklaşım açısından tüm yaşlıların egzersiz programına 
başlamaları için yönlendirilmeleri, devam edebildikleri ve tolere ettikleri kadar uzun süreli aktif kalmalarının sağlanması tüm yaşlılar için son derece önemlidir (Eyigor ve Kutsal, 2010). Ayrıca yaşlilarda fiziksel egzersizi uygun beslenme programlarıyla desteklemek gerekmektedir. Tieland ve diğerleri (2012), 24 hafta boyunca direnç egzersizine ek olarak günde iki kez 15 gr süt proteini alan yaşlılarda kas gücü ve fiziksel performansın geliştiğini belirtmişlerdir. Yaşlılarda protein almak için en iyi zaman fiziksel egzersizden yaklaşık 1 saat sonrasıdır. Bu süreçte en iyi anabolik cevaplar elde edilir (Calvani ve diğerleri, 2013)

Açıkça, her türlü egzersiz programının yaşlıların sağlığını düzeltmede ve morbiditeyi azaltmada anahtar bir rolü vardır. Yaşlıları sağlıksız olan toplumlarda sağlık giderleri kaçınılmaz olarak artmaktadır. Toplumda yaşlılar ne tür egzersizler yapacakları konusunda eğitilmeli ve egzersizi bir yaşam tarzı haline getirmelidirler. Bu konuda eğitimcilere ve sağlık profesyonellerine önemli görevler düşmektedir.

\section{KAYNAKLAR}

Abe, T., Sakamaki, M., Fujita, S., Ozaki, H., Sugaya, M., Sato, Y., \& Nakajima, T. (2010). Effects of low intensity walk training with restricted leg blood flow on muscle strenght and aerobic capacity in older adults. J Geriatr Phys Ther, 33, 34-40. Doi: 10.1097/JPT.0b013e3181d07a73.

Aggarwal, N.T., Wilson, RS., Beck, TL., Bienias, JL., \& Bennett, DL. (2006). Motor dysfunction in mild cognitive impairment and the risk of incident alzhemier disease. Arch Neurol, 63, 1763-1769. Doi:10.1001/archneur.63.12.1763.

Arpacı, F. (2005). Farklı boyutlarılla yaşlılık. Ankara: Türkiye İşçi Emeklileri, Derneği Eğitim Kültür Yayınlar1. s.35-36.

Audelin, M. C., Savage, P. D., \& Ades, P. A. (2008). Exercise-based cardiac rehabilitation for very old patients ( $\geq 75$ years): Focus on physical function. Journal of cardiopulmonary rehabilitation and prevention, 28(3), 163-173. Doi: 10.1097/01.HCR.0000320066.58599.e5.

Baker, L. D., Frank, L. L., Foster-Schubert, K., Green, P. S., Wilkinson, C. W., McTiernan, A., ... \& Duncan, G. E. (2010). Effects of aerobic exercise on mild cognitive impairment: a controlled trial. Archives of neurology, 67(1), 71-79. Doi: 10.1001/archneurol.2009.307.

Barnett, A., Smith, B., Lord, S.R., Willams, M., \& Baumand, A. (2003). Community based group exercise improves balance and reduce falls in at risk older people: a randomised controlled trial. Age and Ageing, 32(4), 407-414. Doi: 10.1093/ageing/32.4.407.

Bean, J.F., Vora, A., \& Frontera, W.F. (2004). Benefits of exercise for community dwelling older adults. Archives of physical medicine and rehabilitation, 85, 31-42. Doi: 10.1016/j.apmr.2004.03.010.

Bird, M., Hill, K. D., Ball, M., Hetherington, S., \& Williams, A. D. (2011). The long-term benefits of a multicomponent exercise intervention to balance and mobility in healthy older adults. Archives of gerontology and geriatrics, 52(2), 211-216. Doi: 10.1016/j.archger.2010.03.021.

Boonen, S., Reginster, J. Y., Kaufman, J. M., Lippuner, K., Zanchetta, J., Langdahl, B., ... \& Eriksen, E. (2012). Fracture risk and zoledronic acid therapy in men with osteoporosis. New England Journal of Medicine, 367(18), 1714-1723. Doi: 10.1056/NEJMoa1204061. 
Bottaro, M., Machado, S. N., Nogueira, W., Scales, R., \& Veloso, J. (2007). Effect of high versus low-velocity resistance training on muscular fitness and functional performance in older men. European journal of applied physiology, 99(3), 257-264. Doi: 10.1007/s00421-006-0343-1.

Cadore, E.L., Rodríguez-Mañas, L., Sinclair, A., \& Izquierdo, M. (2013). Effects of different exercise interventions on risk of falls, gait ability, and balance in physically frail older adults: a systematic review. Rejuvenation Res, 16(2),105-114. Doi: 10.1089/rej.2012.1397.

Calvani, R., Miccheli, A., Landi, F., Bossola, M., Cesari, M., Leeuwenburgh, C., ... \& Marzetti, E. (2013). Current nutritional recommendations and novel dietary strategies to manage sarcopenia. The Journal of frailty \& aging, 2(1), 38-53.

Cartee, G.D., Hepple, R.T., Bamman, M.M., \& Zierath, J.R. (2016). Exercise promotes healthy aging of skeletal muscle. Cell Met, 23(6), 1034-1015. Doi: 10.1016/j.cmet.2016.05.007.

Carter, N. D., Khan, K. M., McKay, H. A., Petit, M. A., Waterman, C., Heinonen, A., ... \& Kruse, K. (2002). Community-based exercise program reduces risk factors for falls in 65-to 75-year-old women with osteoporosis: randomized controlled trial. Canadian Medical Association Journal, 167(9), 997-1004.

Chodzko-Zaiko, W.J. (1997). The World Health Organization issues guidelines for promoting physical activity among older persons. Journal of Aging and Physical Activity,5(1),1-8.

Chodzko-Zaiko, W.J., Proctor, D.N., Singh, M.A., Minson, C.T., Nigg, C.R., \& Salem, G.J. (2009). American college of sport medicine position stand. Exercise and physical activity for older adults. Med Sci Sport Exerc, 41, (17), 1510-1530. Doi: 10.1249/MSS.0b013e3181a0c95c.

Choi, J.H., \& Kim, N.J. (2015). The effects of balance training and ankle training on the gait of elderly people who have fallen. J Phys Ther Sci, 27(1), 39-142. Doi:10.1589/jpts.27.139.

Coats, A.J.S., Forman, D.E., Haykowsky, M., Kitzman, D.W., McNeil, A., Campbell, T.S., \& Arena, R. (2017). Physical function and exercise training in older patients with heart failure. Nat Rev Cardiol, 14(9), 550559. Doi: $10.1038 /$ nrcardio.2017.70.

Colcombe, S. J., Erickson, K. I., Raz, N., Webb, A. G., Cohen, N. J., McAuley, E., \& Kramer, A. F. (2003). Aerobic fitness reduces brain tissue loss in aging humans. The Journals of Gerontology Series A: Biological Sciences and Medical Sciences, 58(2), M176-M180. Doi: 10.1093/gerona/58.2.M176.

Cruz-Jentoft, A. J., Baeyens, J. P., Bauer, J. M., Boirie, Y., Cederholm, T., Landi, F., ... \& Topinková, E. (2010). Sarcopenia: European consensus on definition and diagnosis: Report of the european working group on sarcopenia in older people. Age and ageing, 39(4), 412-423. Doi: 10.1093/ageing/afq034.

Csapo, R., \& Alegre, L.M. (2016). Effects of resistance training with moderate vs heavy loads on muscle mass and strength in the elderly: A meta-analysis. Scand J Med Sci Sports, 26(9), 995-1006. Doi: $10.1111 /$ sms. 12536.

Çilingir, D., ve Bulut, E. (2017). Yaşıı bireylerde ağrıya yaklaşım. Anadolu Hemşirelik ve Sağlık Bilimleri Dergisi, 2017, 2, 144-153.

Dai, X., Hummel, S.L., Salazar, J.B., Taffet, G.E., Zieman, S. \& Schwartz, J.B. (2015). Cardiovascular physiology in the older adults. J Geriatr Cardiol, 12(3), 196-201. Doi: 10.11909/j.issn.16715411.2015.03.015.

Delmonico, M.J., Harris, T.B., Lee, S.J., Visser, M., Nevitt, M., Kritchevsky, S.B., \& Newman A.B. (2007). Alternative definitions of sarcopenia, lower extremity performance, and functional impairment with aging in older men and women. $J$ Am Geriatr Soc, 55(5), 769-774. Doi: 10.1111/j.15325415.2007.01140.x.

Diab, D.L., Watts N.B. (2013). Postmenopausal osteoporosis. Curr Opin Endocrinol Diabetes Obes, 20(6):501509. Doi: 10.1097/01.med.0000436194.10599.94 
Dunsky, A. \& Netz, Y. (2012). Physical activity and sport in advanced age: is it risky?- a summary of data from articles published between: 2000-2009. Curr Aging Sci, 5(1), 66-71. Doi: $10.2174 / 1874609811205010066$.

Elosua, R., Bartali, B., Ordovas, J. M., Corsi, A. M., Lauretani, F., \& Ferrucci, L. (2005). Association between physical activity, physical performance, and inflammatory biomarkers in an elderly population: the InCHIANTI study. The Journals of Gerontology Series A: Biological Sciences and Medical Sciences, 60(6), 760-767.

Elsawy, B., Higgins, KE. (2010). Physical Activity Guidelines for Older Adults. Am Fam Physician, 81(1):5559.

Erickson, K., Miller, D.L., \& Roecklein, K.L. (2012). The aging hippocampus: interactions between exercise, depression and BDNF. The Neuroscients, 18(1), 82-92. Doi: 10.1177/1073858410397054.

Erickson, K., Prakash, P.R., Voss, M.W., Chaddock, L., \& Hu, L. (2009). Aerobic fitness is associated with hippocampal volume in eldery humans. Hippocampus, 19(10), 1030-1039. Doi: 10.1002/hipo.20547.

Espinoza, S., \& Waltson, J.D. (2005). Frailty in older adults: insights and interventions. Cleveland Clinic Journal of Medicine, 72(12), 1105-1112.

Eyigor, S., \& Kutsal, Y. G. (2010). Approach to the frail elderly. Turkish Journal of Physical Medicine and Rehabilitation, 56(3), 135-141.

Eyigor, S., Karapolat, H., Durmaz, B., Ibisoglu, U., \& Cakir, S. (2009). A randomized controlled trial of Turkish folklore dance on the physical performance, balance, depression and quality of life in older women. Archives of gerontology and geriatrics, 48(1), 84-88. Doi: 10.1016/j.archger.2007.10.008.

Eyüboğlu, C., Şişli, Z., \& Kartal, M. (2012). Yaşam döngüsünde yaşl1lığın psikolojik boyutu. Turkish Family Physician, 3(1), 18-22.

Fernandez-Bustamante, A., Sprung, J., Cartin-Ceba, R., Weingarten, T.N., Warner, D.O. (2018) The Aging Respiratory System: Strategies to Minimize Postoperative Pulmonary Complications. In: Reves J., Barnett S., McSwain J., Rooke G. (eds) Geriatric Anesthesiology. USA: Springer, Cham.

Finkelstein, J. S., Brockwell, S. E., Mehta, V., Greendale, G. A., Sowers, M. R., Ettinger, B., ... \& Neer, R. M. (2008). Bone mineral density changes during the menopause transition in a multiethnic cohort of women. The Journal of Clinical Endocrinology \& Metabolism, 93(3), 861-868. Doi: 10.1210/jc.20071876.

Fleg, J.L. (2017). Exercise therapy for older heart failure patients. Heart Fail Clin, 13(3), 607-617. Doi: 10.1016/j.hfc.2017.02.012.

Fleg, J. L., Morrell, C. H., Bos, A. G., Brant, L. J., Talbot, L. A., Wright, J. G., \& Lakatta, E. G. (2005). Accelerated longitudinal decline of aerobic capacity in healthy older adults. Circulation, 112(5), 674682. Doi: 10.1161/CIRCULATIONAHA.105.545459.

Forte, R., Boreham, A.G., Leite, J.C., De Vito, G., Brennan, L., Gibnet, E.R., \& Presce, C. (2013). Enhancing cognitive functioning in the eldery: multicomponent vs resistance training. Clin Int in Ageing, 2013(8), 19-27.

Fried, L. P., Xue, Q. L., Cappola, A. R., Ferrucci, L., Chaves, P., Varadhan, R., ... \& Blaum, C. S. (2009). Nonlinear multisystem physiological dysregulation associated with frailty in older women: implications for etiology and treatment. Journals of Gerontology Series A: Biomedical Sciences and Medical Sciences, 64(10), 1049-1057. Doi: 10.1093/gerona/glp076.

Gokkaya, N.K.O. (2009). Exercise for the eldery: Neither feast nor famine. Turk J Phys Med Rehab, 55, 92-94.

Goldspink, D.F. (2005). Ageing and activity: their effects on the functional reserve capacities of the heart and vascular smooth and skeletal muscles. Ergonomics, 48, 11-14. Doi: 10.1080/00140130500101247. 
Hadem, I.K.H., Majaw, T., Kharbuli, B., \& Sharma, R. (2017). Beneficial effects of dietary restriction in aging brain. J Chem Neuroanat. https://doi.org/10.1016/j.jchemneu.2017.10.001.

Hardy, S.E., Perera, S., Roumani, Y.F., Chandler, J.M., \& Studenski, S.A. (2007). Improvement in usual gait speed predicts beter survival in older adults. J Am Geriatr Soc, 55, 1727-1734. Doi: 10.1111/j.15325415.2007.01413.x.

Hasselgren, L., Olsson, L.L., \& Nyberg, L. (2011). Is leg muscle strenght correlated with functional balance and mobility among inpatientin geriatric rehabilitation?. Arch Gerontol Geriatr, 3, 220-225. Doi: 10.1016/j.archger.2010.11.016.

Hautier, C., \& Bonnefoy, M. (2007). Training for older adults. Ann Readapt Med Phys, 50, 469-154. Doi: 10.1016/j.annrmp.2007.04.018.

Hawkins, S., \& Wiswell, R. (2003). Rate and mechanism of maximal oxygen consumption decline with aging. Sport Med, 33, 877-888.

Henry, K.D., Rosemond, C., \& Eckert, L.B. (1999). Effect of number of home exercises on compliance and performance in adults over 65 years of age. Phys Ther, 79, 270-277.

Hillman, C.H., Eriksonn, K.I., \& Kramer, A.F. (2008). Be smart, exercise your heart: exercise effects on brain and cognition. Neurscience, 9, 58-65. Doi: 10.1038/nrn2298.

Hollmann, W., Strüder, H.K., Tagarakis, C.V.M., \& King, G. (2007). Physical activity and the eldery. Eur Journal Cardio Prevention and Rehab, 14, 730-739. Doi: 10.1097/HJR.0b013e32828622f9.

Hooghiemstra, A.M., Eggermont, L.H., Scheltens, P., van der Flier, W.M., \& Scherder, E.J. (2012). Exercise and early-onset Alzheimer's disease: theoretical considerations. Dement Geriatr Cogn Dis Extra, 2, 13245. Doi: $10.1159 / 000335493$.

Hunter, G.R., Bickel, C.S., Fischer, G., Neumeier, W.H., \& Macarthy, J.P. (2013). Combined aerobic/strenght training and energy expenditure in older women. Med Sci Sport Exerc, 45(7), 123-128. Doi: 10.1249/MSS.0b013e3182860099.

Iliffle, S., Kendrick, D., Morris, R., Skelton, D., Gage, H., Dinan, S.... \& Masut, T. (2010). Multi centre cluster randomised trial comparing a community group exercise programme with home based exercise with usual care for people aged 65 and over in primary care: protocol of the proact +65 trial. Trials, 11, 2-12. Doi: 10.1186/1745-6215-11-6.

James, B.D., Boyle, P.A., Buchman, A.S., Barnes, L.L., \& Bennett, D.A. (2011). Life space and risk of Alzheimer disease, mild cognitive impairment, and cognitive decline in old age. Am J Geriatr Psychiatry, 19(11), 961-969. Doi: 10.1097/JGP.0b013e318211c219.

Kai, M.C., Anderson, M., \& Lau, E.M. (2003). Exercises interventions: defusing the world's osteoporosis time bomb. Bullet World Org, 81(11), p.827-830.

Katula, J.A., Rejeski, W.J., \& March A.P. (2008). Enhancing quality of life in older adults: a comparison of muscular strenght and power training. Health Qual Life Outcomes, 6, 45. Doi: 10.1186/1477-7525-6-45.

Kuramato, A.M. (2006). Therapeutic benefits of tai chi exercise: research rewiev. WMJ. 105(7), 42-46.

Lautenschlager, N.T., Cox, K.L., Flicker, L., Foster, J.K., van Bockxmeer F.M., Xiao J..... \& Almeida O.P. (2008). Effects of physical activity on cognitive function in older adults at risk for Alzheimer disease: a randomized trial. JAMA, 300(9), 1027-1037. Doi: 10.1001/jama.300.9.1027.

Legrand, F.D. \& Mille, C.R. (2009). The effects of 60 minutes of supervised weekly walking (in a single vs. 3-5 session format) on depressive symptoms among older women: Findings from a pilot randomized trial. Ment Health Phys Act, 2(2), 71-75. Doi:10.1016/j.mhpa.2009.09.002. 
Lesinski, M., Hortobágyi, T., Muehlbauer, T., Gollhofer, A., \& Granacher, U. (2015). Effects of balance training on balance performance in healthy older adults: a systematic review and meta-analysis. Sports Med, 45(12), 1721-1738. Doi: 10.1007/s40279-015-0375-y.

Li, F., Fisher, K.J., \& Harmer, P. (2005). Improving physical function and blood pressure in older adults through cobblestone mat walking: a randomized trial. J Am Geriatr Soc, 53(8), 1305-1312. Doi: 10.1111/j.15325415.2005.53407.x.

Li, F., Harmer, P., Wilson, N., \& Fisher, K.J. (2003). Health benefits of cobblestone-mat walking: preliminary findings. J Aging Phys Activity, 11(4), 488-502.

Licata, A.A., \& Williams, S.E. (2103). What is osteoprosis?. A DXA Primer for the Practicing Clinician. Newyork: Springer. p.5-13.

Liu, C.J., \& Latham, N.K. (2009). Progresive resistance strenght training for improving physical function in older adults. Cochrane Database Syst Rev, 8(3),1-270. Doi: 10.1002/14651858.

Liu, P.Y., Brummel-Smith, K., \& Ilıch, J.Z. (2011). Aerobic exercise and whole body vibratation in offsetting bone loss in older adults. J Aging Res, 3, 1-9. Doi: 10.4061/2011/379674.

Low, D.C., Walsh, G.S., \& Arkesteijn, M. (2017). Effectiveness of exercise interventions to improve postural control in older adults: a systematic review and meta-analyses of centre of pressure measurements. Sports Med, 47(1), 101-112. Doi: 10.1007/s40279-016-0559-0.

Maduirera, M.M., Takayama, L., Gallinaro, A.L., Caparbo, V.F., Costa, R., \& Pereira, R.M. (2007). Balance training is highly effective in improving functional status and reducing the risk of falls in eldery women with osteoporosis: a randomized controlled trial. Osteoporos Int, 18(4), 419-422. Doi: 10.1007/s00198006-0252-5.

Marosi, K., Bori, Z., Hart, N., Sárga, L., Koltai, E., Radák, Z., \& Nyakas, C. (2012). Long-term exercise treatment reduces oxidative stress in the hippocampus of aging rats. Neuroscience, 226, 21-28. Doi: 10.1016/j.neuroscience.2012.09.001.

Marzetti, E., Calvani, R., Tosato, M., Cesari, M., Di Bari, M., Cherubini, A..... \& Landi F. (2017). Physical activity and exercise as countermeasures to physical frailty and sarcopenia. Aging Clin Exp Res, 29(1), 35-42. Doi: 10.1007/s40520-016-0705-4.

Mechling, H., \& Netz, Y. (2009). Aging and inactivity -capitalizing on the protective effect of planned physical activity in old age. Eur Rev Aging Phys Act, 6, 89-97.

Melzer, I., Benjuya, N. \& Kaplanski, J. (2003). Effects of regular walking on postural stability in the elderly. Gerontology, 49(4), 240-245. Doi: 10.1159/000070404.

Nair, K.S. (2005). Aging muscle. Am J Clin Nutr, 81(5), 953-963. Doi: 10.1093/ajcn/81.5.953.

Narici, M.V., \& Maganaris, C.N. (2006). Adaptability of eldery human muscles and tendons to increased loading. J Anat, 208(4), 433-443. Doi: 10.1111/j.1469-7580.2006.00548.x.

Nelson, M.E., Rejeski, W.J., Blair, S.N., Duncan, P.W., Judge, J.O., King, A.C..... \& Castaneda-Sceppa C. (2007). Physical activity and public health in older adults: recommedation from the american college of sport medicine and the american heart association. Med Sci Sports Exerc, 39(8), 1434-1445. Doi: 10.1249/mss.0b013e3180616aa2.

Nied, R.J., \& Franklin, B. (2002). Promoting and prescribing exercise for the eldery. Am Fam Phys, 65(3), 419427.

Novotny, S.A., Warren, G.L., \& Hamrick, M.W. (2015). Aging and the muscle-bone relationship. Physiology, 30(1), 8-16. Doi: 10.1152/physiol.00033.2014. 
Oliveira, L.C., Oliveira, R.G., \& Pires-Oliveira, D.A. (2016). Comparison between static stretching and the Pilates method on the flexibility of older women. J Bodyw Mov Ther, 20(4), 800-806. Doi: 10.1016/j.jbmt.2016.01.008.

Ozaki, K., Kondo, I., Hirano, S., Kagaya, H., Saitoh, E., Osawa, A., \& Fujinori, Y. (2017). Training with a balance exercise assist robot is more effective than conventional training for frail older adults. Geriatr Gerontol Int, 17(11), 1982-1990. Doi: 10.1111/ggi.13009.

Papa, E.V., Dong, X., \& Hassan, M. (2017). Skeletal muscle function deficits in the elderly: current perspectives on resistance training. $J$ Nat Sci, 3(1), 272.

Reynolds, C.F., Dew, M.A., Pollock, B.G., Mulsant, B.H., Frank, E., Miller, M.D..... \& Kupfer D.J. (2006). Maintenance treatment of major depression in old age. $N$ Eng J Med, 354(11), 1130-1138. Doi: 10.1056/NEJMoa052619.

Roubenoff, R. (2003). Sarcopenia: effects on body composition and function. J Gerontol A Biol Sci Med Sci, $58(11), 1012-1017$.

Rosano, C., Venkatraman, V.K., Guralnik, J., Newman, A.B., Glyn, N.W., Launer, L..... \& Aizenstein H. (2010). Physcomotor speed and functional brain mr1 2 years after completing a physical activity treatment. J Gerontol Biol Sci Med, 65(6), 639-647. Doi: 10.1093/gerona/glq038.

Saini, A., Faulkner, S., Al-Shanti, N., \& Stewart, C. (2009). Powerfull signals for weak muscles. Ageing Res Rev, 8(4), 251-267. Doi: 10.1016/j.arr.2009.02.001.

Skloot, G.S. (2017). The Effects of aging on lung structure and function. Clin Geriatr Med, 33(4), 415-457. Doi: 10.1016/j.cger.2017.06.001.

Soyuer, F., ve Soyuer, A. (2008). Yaşl111k ve fiziksel aktivite. İnönü Üniversitesi Tip Fakültesi Dergisi, 15, 219224.

Stathokostas, L., Jacob-Johnson, S., Patrella, R.J., \& Paterson, D.H. (2004). Longutidinal changes aerobic power in older men and women. J Appl Physiol, 97(2), 791-798. Doi: 10.1152/japplphysiol.00447.2003.

Strawbridge, W.J., Deleger, S., Roberts, R.E., \& Kaplan, G.A. (2002). Physical activity reduces the risk of subsequent depression for older adults. Am J Epidemiol, 156(4), 328-334. Doi: 10.1093/aje/kwf047.

Sui, X., LaMonte, M.J., Laditka, J.N., Hardin, J.W., Chase, N., Hooker, S.P., \& Blair S.N. (2007). Cardiorespiratory fitness and adiposity as mortality predictors in older adults. JAMA, 298(21), 25072516. Doi: 10.1001/jama.298.21.2507.

Taggart, H.M. (2002). Effects of Tai Chi Exercise on Balance, Functional Mobility and Fear of Falling Among Older Women. Appl Nurs Res, 15(4), p.235-242. Doi: 10.1053/apnr.2002.35975.

Taylor, A.H., Cable, N.T., Faulkner, G., Hillsdon, M., Narici, M., \& Van Der Bij, A.K. (2004). Physical activity and older adults: a review of health benefits and the effectiveness of interventions. J Sports Sci, 22(8), 703-725. Doi: 10.1080/02640410410001712421.

Tieland M, Dirks M.L, van der Zwaluw N., Verdijk, L.B., van de Rest, O... \& Van Loon L.J. (2012). Protein supplementation increases muscle mass gain during prolonged resistance-type exercise training in frail elderly people: a randomized, double-blind, placebo-controlled trial. J Am Med Dir Assoc, 13(8), 713719. Doi: 10.1016/j.jamda.2012.05.020.

Tilley, A.E., Walters, M.S., Shaykhiev, R., \& Crystal, R.G. (2015). Cilia dysfunction in lung disease. Annu Rev Phyisiol, 77, 379-406. Doi: 10.1146/annurev-physiol-021014-071931.

Topinkova, E. (2008). Aging, disability and frailty. Ann Nutr Metab, 52, 6-11. Doi: 10.1159/000115340. 
Vainionpaa, A., Korpelainen, R., Siavinen, H., Vihriala, E., Leppaluoto, J., \& Jamsa, T. (2007). Effect of impact exercise and its intensity on bone geometry at weight bearing tibia and femur. Bone, 40(3), 604-611. Doi: 10.1016/j.bone.2006.10.005.

Visser, M., Pahor, M., Taaffe, D.R., Goodpaster, B.H., Simonsick, E.M., Newman, A.B...\& Harris, T.B. (2002). Relationship of interleukin-6 and tumor necrosis factor-alpha with muscle mass and muscle strength in elderly men and women. J Gerontol A Biol Med Sci, 57(5), 326-332.

Vogel, T., Brechat, P.H., Lebretre, P.M., Kaltenbach, G., Berthel, M., \& Londsdorfer, J. (2009). Health benefits of physical activity in older patients: a review. Int J Clin Pract, 62(2), 303-320. Doi: 10.1111/j.17421241.2008.01957.x.

Wang, J., Leung, K.S., Chow, S.K.H., \& Cheung, W.H. (2017). Inflammation and age-associated skeletal muscle deterioration (sarcopenia). J Orthop Trans, 10, 94-101. Doi: 10.1016/j.jot.2017.05.006.

Williams, M.A., Fleg, J.L., Ades, P.A., Chaitman, B.R., Miller, M.H., Mohiuddin, S.M.... \& Wenger, N.K. (2002). Secondary prevention of coronary heart disease in the elderly (with emphasis on patients 75 years of age) : an American heart association scientific statement from the council on clinical cardiology subcommittee on exercise, cardiac rehabilitation, and prevention. Circulation, 105(14), 1735-1743.

Zoghi, M. (2010). Cardiovascular functions in the eldery. Turkish Journal of Geriatrics, special issue, 2, 1-4.

Zou, L., Wang, C., Tian, Z., Wang, H., \& Shu, Y. (2017). Effect of Yang-style Tai Chi on gait parameters and musculoskeletal flexibility in healthy Chinese older women. Sports, 5(3), 2-12. Doi: 10.3390 /sports 5030052 . 